\title{
Forecasting Helicoverpa armigera (Lepidoptera: Noctuidae) larval phenology in pigeonpea and chickpea crops using growing degree days
}

\section{B. KIRAN GANDHI ${ }^{\star}$, S.K. SINGH ${ }^{1}$, KRISHNA KUMAR, S. VENNILA ${ }^{2}$, Y. SRUJANA ${ }^{3}$, ARTIKATIYAR and N.P. SINGH}

\author{
ICAR-Indian Institute of Pulses Research, Kanpur, U.P., India \\ ${ }^{1}$ ICAR-National Research Center for Integrated Farming, Motihari, Bihar, India \\ ${ }^{2}$ ICAR-National Research Center for Integrated Pest Management, New Delhi, India \\ ${ }^{3}$ ARS Groundnut, Acharya N.G. Ranga Agricultural University, Kadiri, A.P., India. \\ ${ }^{*}$ Corresponding author: bkg0530@gmail.com
}

\begin{abstract}
Gram pod borer, Helicoverpa armigera is a serious insect pest of pigeonpea and chickpea crops, responsible for huge economic losses. Timely forecasting and subsequent sensible management practices of $H$. armigera would save the crops from economic damage. In the present study, $H$. armigera larval incidence data was recorded from sixteen pigeonpea and chickpea growing locations (Maharashtra, India) for three seasons (2015, 2016 and 2017). Observed accumulated GDD (from 40 SMW to 7 SMW) revealed, $H$. armigera completed one generation in 29 days to develop 4 generations across the locations and seasons. After accumulating 86GDD (40 SMW) and 62 GDD (43 SMW), larval 'biofix' (initial incidence of larvae) was started in pigeonpea and chickpea, respectively. Logistic regression model estimated accumulated GDD required by $H$. armigera larvae to reach ETL in pigeonpea (629 GDD) and chickpea (378 GDD), which was same as observed accumulated GDD. Statistical criteria viz., Adjusted $r^{2}$, AIC and BIC projected logistic regression model as a better performer in most cases. The geographically unique models developed based on biofix and accumulated GDD in this study can be used for timely advisories and sustainable management of $H$. armigera in pigeonpea and chickpea crops after field validation.
\end{abstract}

Key words: AIC, Boltzmann, BIC, biofix, logistic, regression

Pigeonpea [Cajanus cajan (L.)] is the sixth most important legume crop in the world. India and Myanmar are the major producers (83\%) ahead of Malawi, Tanzania, Kenya and Uganda. Chickpea (Cicer arietinum L.) is the widely cultivated food legume in South Asia and the third largest food legume produced globally. Worldwide, chickpea production averaged 12.09 million tons in 2016. India is a major producer (70\%) over Turkey, Pakistan, Australia, Myanmar, Ethiopia, Iran, Mexico, Canada and United states (FAOSTAT, 2018). More than 200 species of insects feed on chickpea and pigeonpea crops. Most of the insects have a sporadic or restricted distribution, or seldom present at high densities to cause economic losses. On the other hand, some arthropods are devastating on both the crops. One such insect pest is gram pod borer $H$. armigera, the most important constraint to pulse production in Asia, Africa, Australia, and the Mediterranean Europe. A monetary loss in chickpea and pigeonpea worldwide due to H.armigera alone was estimated at more than US\$600 million annually, in spite of several plant protection interventions (Rao et al., 2013).
In India, $H$. armigera has a large number of alternate hosts like chickpea, pigeonpea, marigold, chilli, okra, cottonetc. Genetic Engineering Approval Committee (GEAC) of Government of India (GOI) approved pigeonpea as a refuge crop for $B t$ cotton (Yenagi et. al., 2011). Host availability alone does not determine the abundance and distribution of $H$. armigera; factors like topography, farming practices and climate change will affect the relative phenology and survival. Mironidis and Savopoulou-Soultani (2008) reported that alternating temperature conditions allow $H$. armigera to complete its life cycle over a much wider range of temperature levels than do constant conditions. Phenologies of some insects are changed by climate change (Westgarth-Smith et al., 2007; Parmesan, 2007). Srinivasa Rao and Prasad (2020) observed growth and development of Spodoptera litura are significantly influenced by both lower and higher temperature.

There is a mounting demand for forecasting seasonal occurrence of insects and many mathematical models were developed that describe developmental rates as a function 
of temperature (Wagner et al., 1984). Degree-day models are widely used to predict crop pests and diseases incidence to advocate timely control strategies (Chen et al., 2013). Ziter et al. (2012) opined that models developed on degreedays are sufficient evidences to capture certain important aspects of the biology of insect pests, and are therefore useful abstractions. Chen et al. (2015) observed that change in diurnal temperature range could substantially alter insect life history. Much is known about phenologies of incubating eggs (Dhillon and Sharma, 2007), overwintering pupae (Huang and Li, 2014) and flying adults (Sharpe and DeMichele, 1977) of $H$. armigera worldwide. Yet, forecasting of $H$. armigera larvae as function of growing degree-days has not been modeled on pigeonpea and chickpea. In this study we tried to advance the existing information to forecast the H. armigera larval phenology in pigeonpea and chickpea through degree-days estimation.

\section{MATERIALS AND METHODS}

\section{Study sites and sampling}

Sampling was carried out in sixteen locations (districts) of Maharashtra state, situated in the western and eastern plateau and hills agro-climatic zones of India (Fig.1). From each location, fifty villages were selected with one acre $\left(4000 \mathrm{~m}^{2}\right)$ as a unit of observation in each village. Fixed plot survey was carried daily in selected units during three successive seasons $(2015,2016$ and 2017) starting from October to February in pigeonpea and chickpea crops. The selected units were ensured with good agronomic practices to keep the crop healthy withstanding insecticidal spray. Sampling varied with the crop. In pigeonpea, randomly ten plants were selected from each unit and from each plant three branches located in different directions from middle portion of the plant were selected. The number of larvae per 3 branches was ascertained. In chickpea, number of larvae per one meter row length was observed from selected five random places in the field. Daily average number of larvae on respective crops from each unit in a district was represented as mean larval number per location in a day. Further, mean larval number per location for each Standard Meteorological Week (SMW) was averaged in pigeonpea (from 40 to 03 SMW) and chickpea (from 43 to $07 \mathrm{SMW}$ ) crops. In both the crops, observation was targeted on $3^{\text {rd }}$ in star larvae only as they spent $20 \%$ more time feeding than first instars (Johnson and Zalucki, 2007). Initial larval appearance (biofix) of $H$. armigera across the locations in two crops has been noticed for further model evaluation.

\section{Temperature data sets and calculation of Growing Degree Days(GDD)}

Weather data was obtained from ICAR-Central Research Institute for Dryland Agriculture (CRIDA), Hyderabad, India for the study period (2015 to 2017). Laboratory study conducted by Mironidis and SavopoulouSoultani (2008) showed, that at constant temperatures outside the $17.5-32.5^{\circ} \mathrm{C}$ range did not develop $H$. armigera from egg to adult (emergence), while alternating conditions expanded this range from 10 to $35^{\circ} \mathrm{C}$. In the present study, the Lower Development Threshold (LDT) temperature $12.6^{\circ} \mathrm{C}$ (Hartstack et al., 1976) specific to H. armigera was considered for calculating GDD, while upper temperature threshold was set to $42^{\circ} \mathrm{C}$. A more precise method-sine wave curve horizontal cut-off method was used to compute GDD. This method takes the dailyminimum, maximum, and baseline temperatures (lower threshold) to estimate the GDD (http:/ /ipm.ucanr.edu/WEATHER/index.html).Expected number of $H$. armigera generations and generation time was estimated by considering GDD required for completing one generation time (from egg to adult stage) i.e., 422.3 degree-days (Hartstack et al., 1976). Based on biofix and LDT, growing degree-days required by $H$. armigera to attain Economic Threshold Level (ETL) was computed across the locations in pigeonpea and chickpea crops.

\section{Generations and generation time}

A two-way analysis of variance (ANOVA) was performed to determine the influence of seasons and locations on mean larval number on pigeonpea and chickpea, Temperature Maximum (Tmax.), Temperature Minimum (Tmin.), GDD, Generation (G) and Generation Time (GT). The observed cumulative mean larval number and estimated accumulated GDD were subjected to ANOVA for each month separately. Tukey's multiple comparison test was employed to compare means and Levene's test for analyzing homogeneity of variance (Sokal and Rohlf, 1995).

\section{Fitting phenological models}

The non-linear regression models (Boltzmann and Logistic equations) developed by Damos and SavopoulouSoultani (2010) were employed to describe the relationship between accumulated GDD and the larval cumulative incidence. In order to assess assumptions of independency and normality of the error term, a residual analysis was performed (Sokal and Rohlf, 1995).

Based on three parameters 'Boltzmann' type equation 


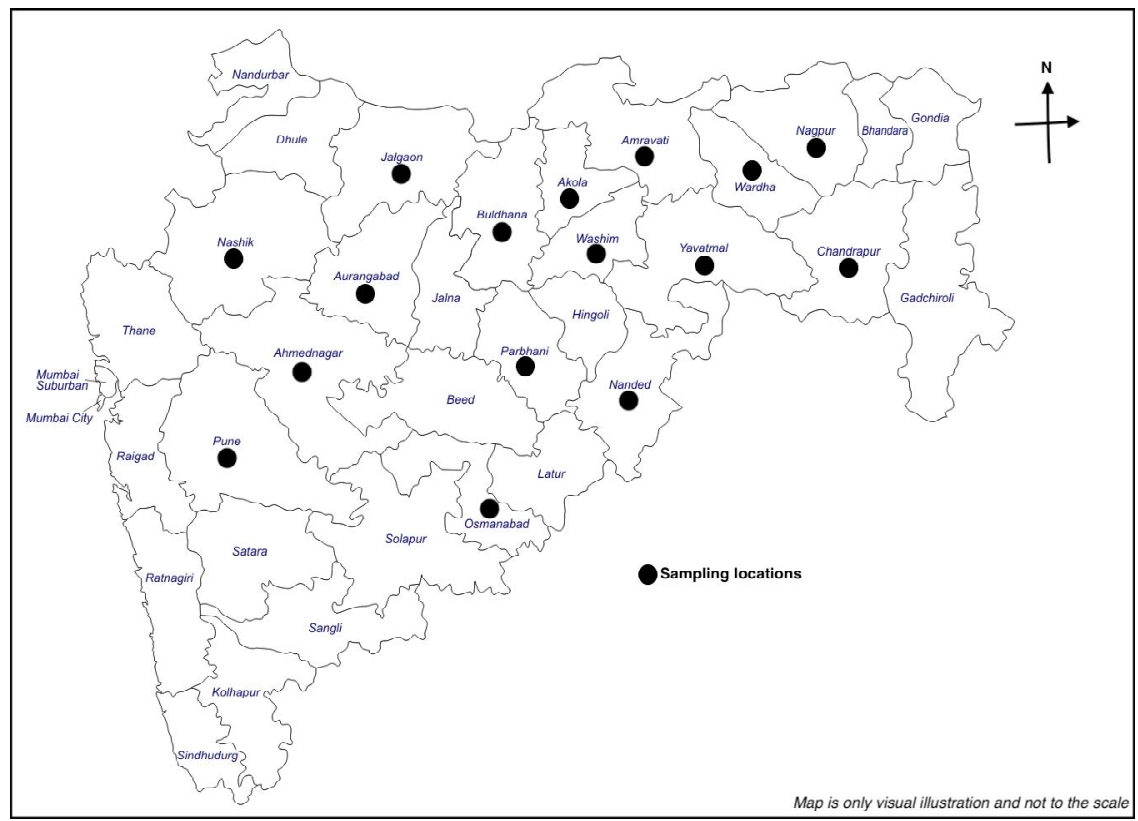

Fig. 1: Outline map of Maharashtra state representing sampling sites

was fitted to data. $f(x)=\frac{a}{1+e^{((-x-c) / b)}}$

Based on a four parameters 'Logistic' type regression function was fitted to data.

$$
g(x)=d+\frac{a}{1+[x / c]^{b}}
$$

In all the cases, parameter estimation was based on an iterative Ordinary Least Square (OLS) method, using the Levenberge-Marquard algorithm, in which the observed cumulative larval number was treated as the dependent variable. Regressed predicted values and residuals were obtained by fitting above equations with the respective observed cumulative larval number and estimated parameters (SPSS, 1997). Both Eq. (1) and Eq. (2) were fitted with estimated parameters and the number of accumulated GDD required for $H$. armigera to reach ETL was observed. Further, the estimated GDD was compared with natural GDD accumulation needed to attain ETL in field condition.

\section{Statistical evaluation of model}

The models developed were fitted with (both observed and predicted) cumulative larval number and evaluated for performance comparisons, which are based on the adjusted coefficient of determination (Adj. $\mathrm{r}^{2}$ ) and on the Akaike's Information Criteria (AIC) and Bayes-Schwartz Information Criteria (BIC) (Kvalseth, 1985; Quinn and Keough, 2002).
Adj. $r^{2}$ is defined as:

$$
A d j r^{2}=1-\frac{(R S S / n-(\theta+1))}{S S / n-1}
$$

where $R S S$ is the residual sum of squares; $S S$, the total sum of squares; and $n$ the number of observations (Kvalseth, 1985; Richmond and Bacheler, 1989). AIC developed and proposed by Akaike (1974) is a measure of the goodness of fit of an estimated statistical model and is grounded on the concept of entropy (Burnham and Anderson, 2002; Quinn and Keough, 2002):

$$
A I C=n[\ln (R S S)]-[n-2(\theta+1)]-n \ln (n)
$$

The BIC (Schwartz, 1978), is an increasing function of the root mean square error (Quinn and Keough, 2002):

$$
B I C=n[\ln (R S S)]+(\theta+1) \ln (n)-n \ln (n)
$$

where, $R S S$ is the residual sum of squares and $S S$ the total sum of squares and $n$ the number of observations.

The BIC penalizes free parameters more strongly than does the AIC (Burnham and Anderson, 2002; Quinn and Keough, 2002).

\section{RESULTS AND DISCUSSION}

Temperature, generations, generation time and growing degree-days across locations

A considerable variation across sixteen locations and 


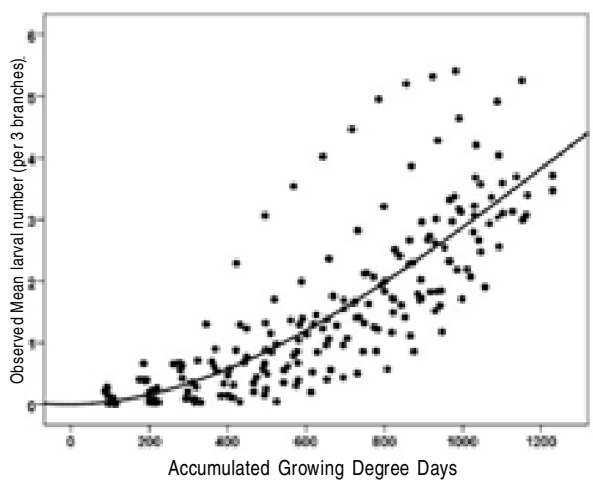

(a)

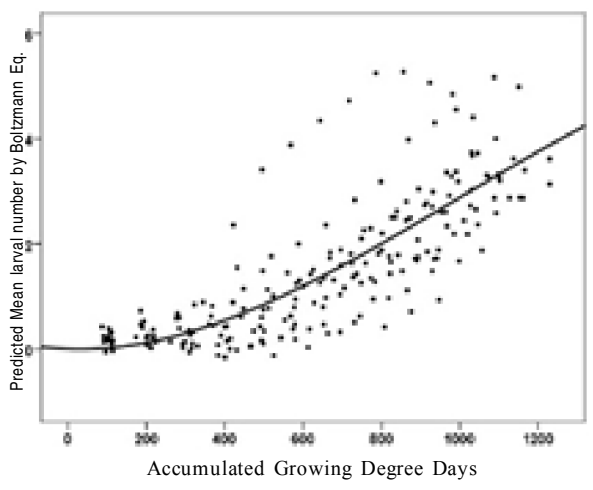

(b)

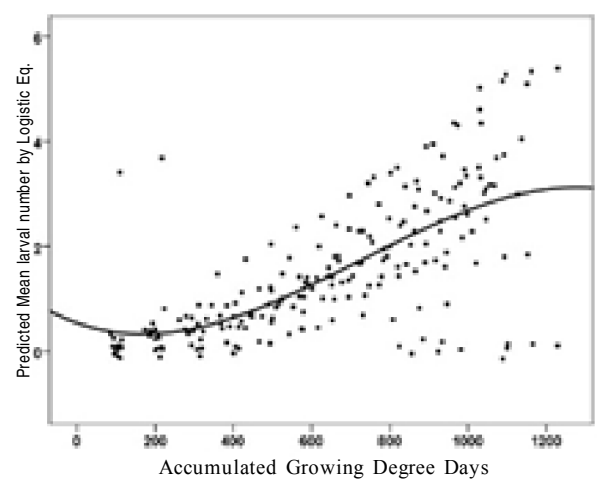

(c)

Fig. 2: Scattered plot illustrating the pooled model fit of mean larval number per 3 branches with accumulated growing degreedays in pigeonpeain (a) Observed (b) Boltzmann and (c) Logistic equation

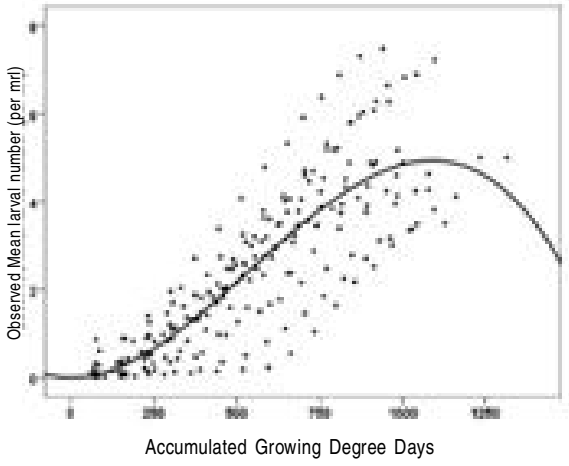

(a)

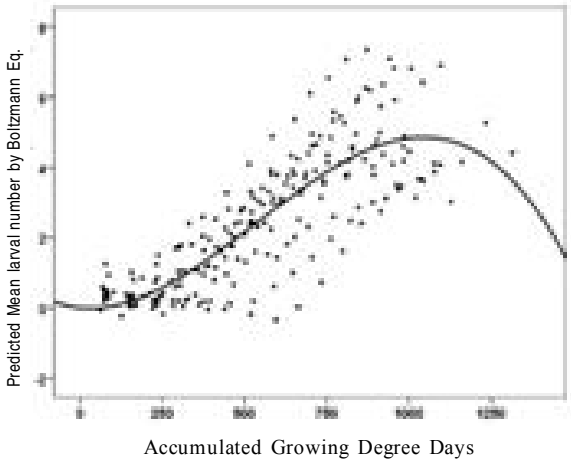

(b)

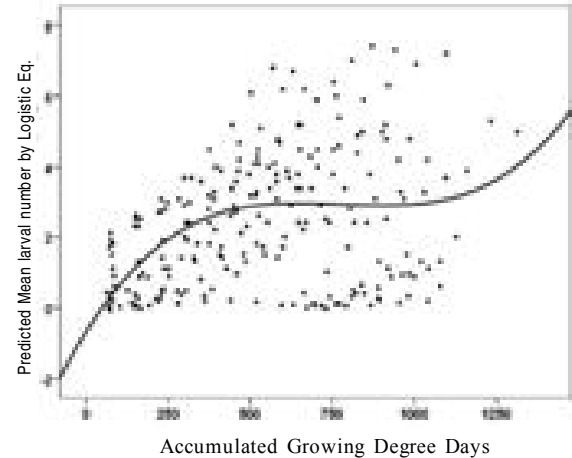

(c)

Fig. 3: Scattered plot illustrating the pooled model fit of mean larval number per meter row length with accumulated growing degree-days in chickpea in (a) Observed (b) Boltzmann and (c) Logistic equation

three seasons was observed for minimum $(\mathrm{F}=6.42 ; \mathrm{df}=2,15$; $p<0.05$ and $\mathrm{F}=20.21 ; \mathrm{df}=2,15 ; p<0.05)$ and maximum $(\mathrm{F}=14.34 ; \mathrm{df}=2,15 ; p<0.05$ and $\mathrm{F}=57.24 ; \mathrm{df}=2,15 ; p<0.05)$ temperatures. Higher minimum and maximum temperatures were noticed in Washim and Jalgaon locations, respectively. Rise in day mean minimum $\left(17.6^{\circ} \mathrm{C}\right)$ and maximum $\left(32.5^{\circ} \mathrm{C}\right)$ temperatures were noticed during 2015. The highest estimated mean accumulated GDD were observed at Chandrapur (1716.4) location and during 2015 season (1766.8). There was significant difference $(\mathrm{F}=11.16$; $\mathrm{df}=2,15 ; p<0.05$ and $\mathrm{F}=187.07 ; \mathrm{df}=2,15 ; p<0.05$ ) for accumulated GDD between locations and seasons. Number of generations $(\mathrm{F}=11.6 ; \mathrm{df}=2,15 ; p<0.05$ and $\mathrm{F}=186.88$, $\mathrm{df}=2,15 ; p<0.05)$ and generation time $(\mathrm{F}=11.64 ; \mathrm{df}=2,15$; $p<0.05$ and $\mathrm{F}=169.44, \mathrm{df}=2,15 ; p<0.05$ ) of $H$. armigera varied considerably between locations and seasons. More number of $H$. armigera generations coupled with shortened generation time was noticed from Chandrapur location (4.07 G; 32.99 days GT) and during 2015 season (4.18 G; 31.9 days GT) (Table 1).

Differences in number of generations and generation time of $H$. armigera across the locations and seasons might be attributed to variations in day mean temperatures. Similar observation was made by Srinivasa Rao et al. (2016) on number of generations and generation time of $H$. armigera larva for future climate data on pigeonpea. In current study, erroneous degree-day estimates between locations and seasons was ascribed to changes in day air temperatures, whereas Kuhrt et al. (2006) explained the defective estimate of degree-days as a comparable difference between microhabitat and ambient air temperatures. Higher incidence of $H$. armigera larvae on pigeonpea was linked to temperature rise across the locations and seasons, which was supported by laboratory study conducted by Akbar et al. (2016), where increased temperature had negative effect on $H$. armigera larval survival, larval period, pupal weight and pupal period, and a positive effect on larval growth. Weather based prediction models of $H$. armigera larval population on soybean developed by Ram Manohar et al. (2019) revealed, maximum temperature $\left(27.48-31.44^{\circ} \mathrm{C}\right)$ favored their peak incidence. Conversely Mironidis and SavopoulouSoultani (2008) observed that extreme temperatures had 


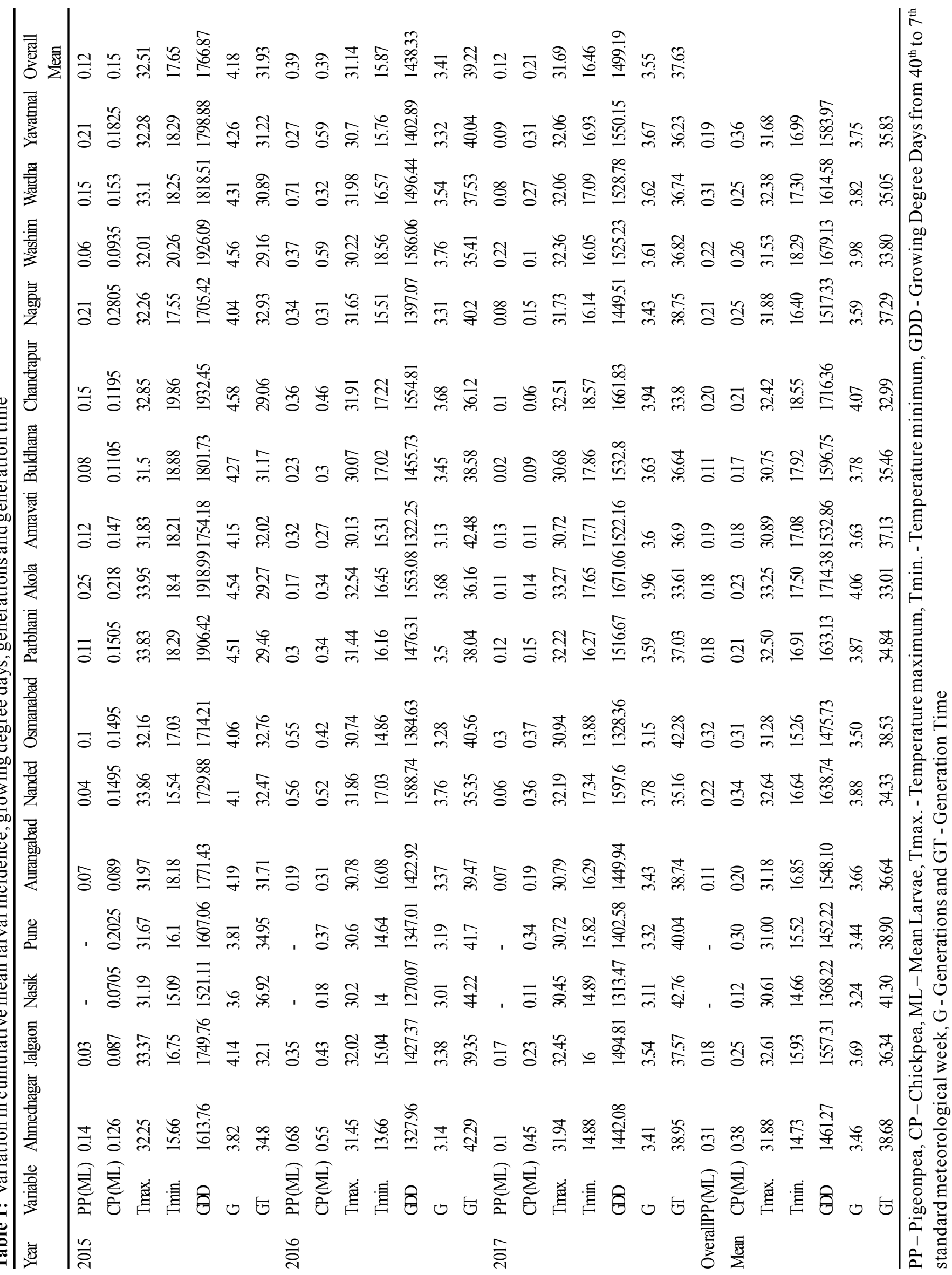




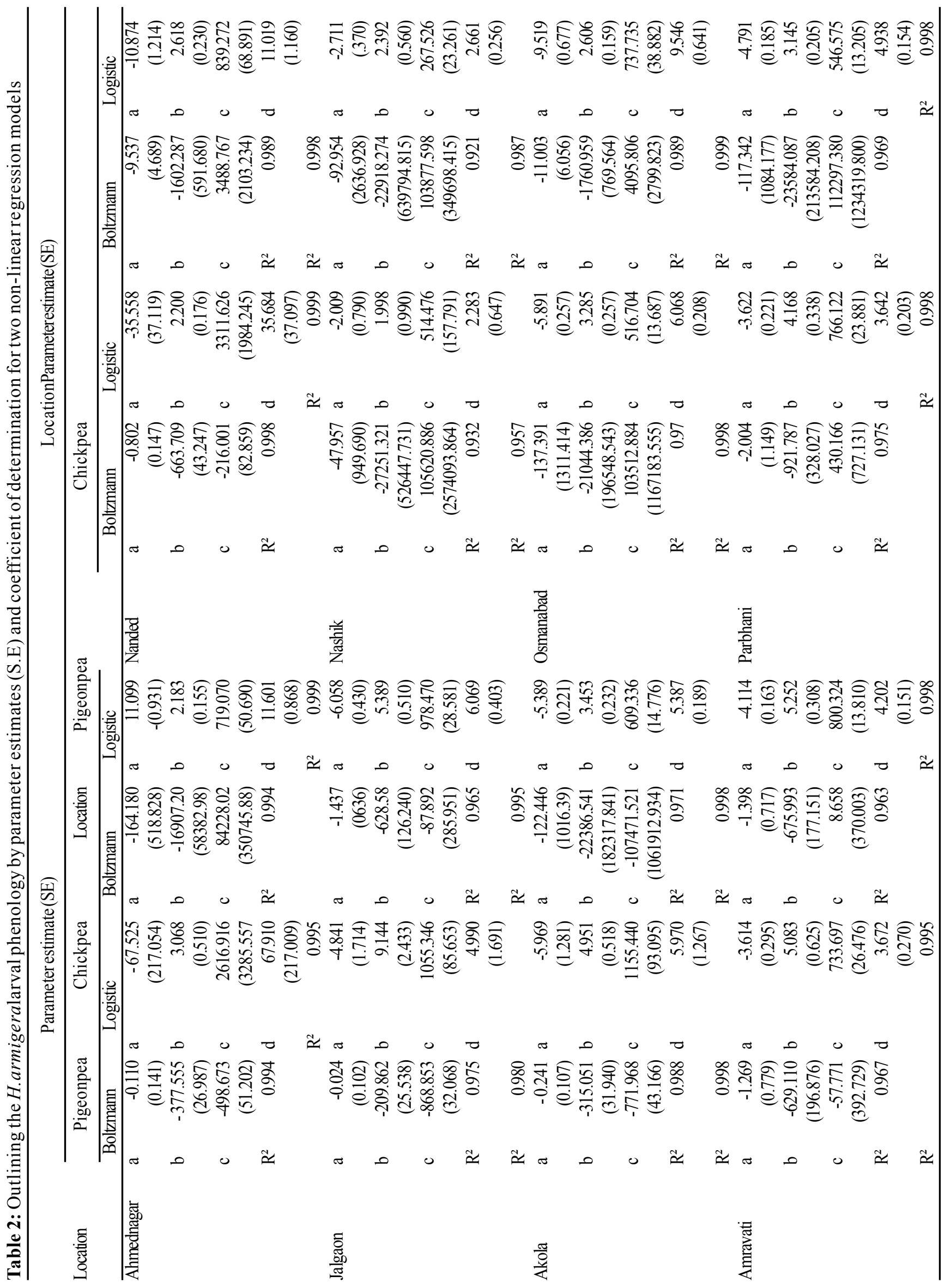




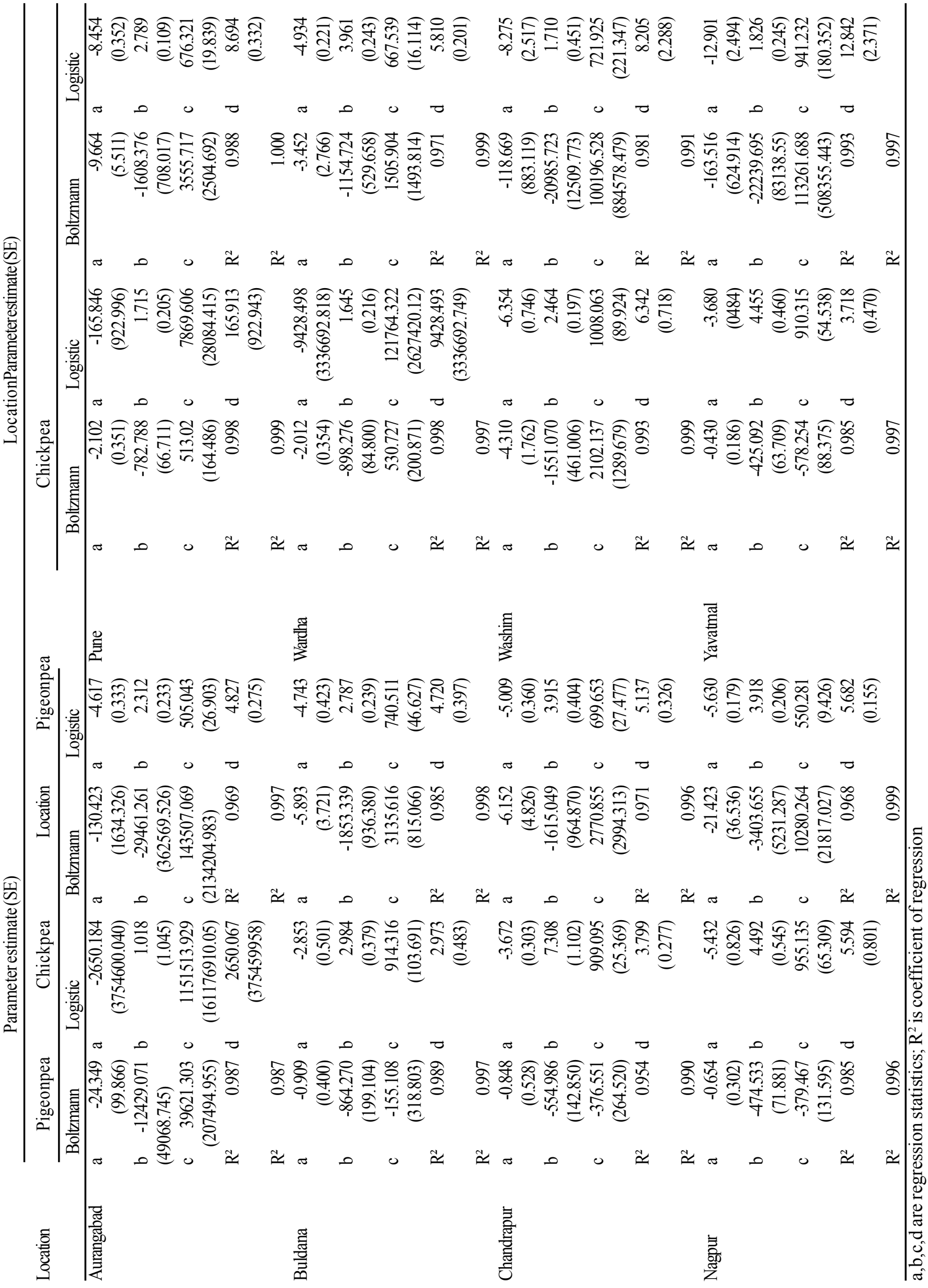




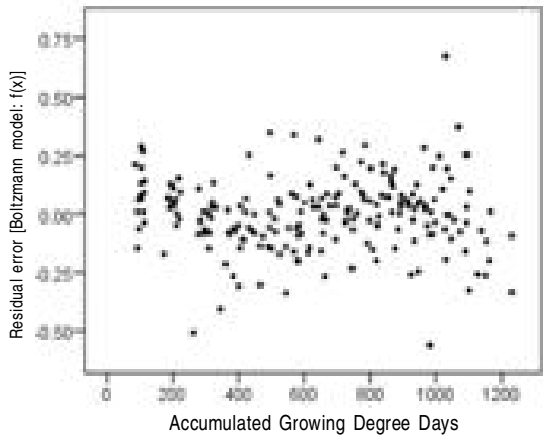

(a)

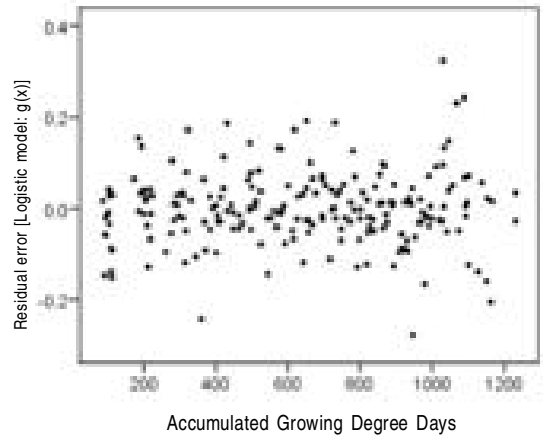

(b)

Fig. 4: Residual error plot for generated (a) Boltzmann and (b) Logistic models in describing cumulative mean number of $H$. armigera larvae on pigeonpea

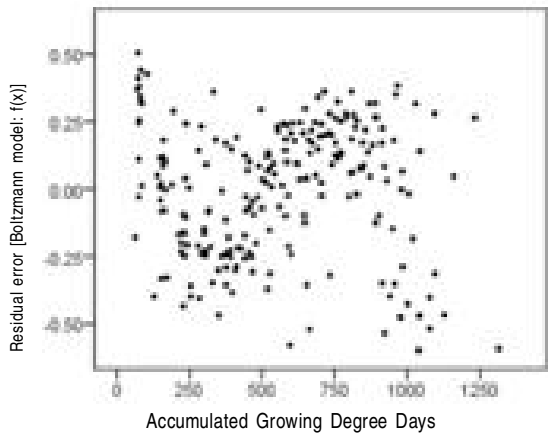

(a)

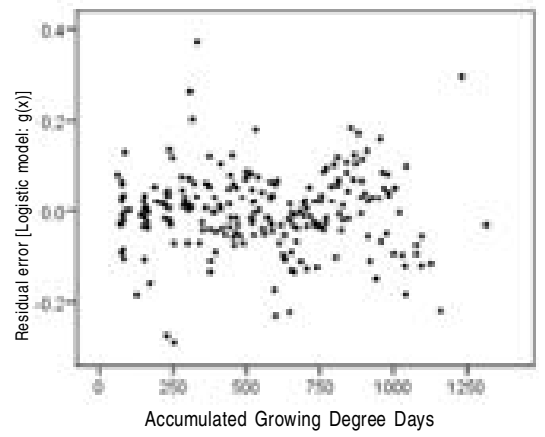

(b)

Fig. 5: Residual error plot for generated (a) Boltzmann and (b) Logistic models in describing cumulative mean number of $H$. armigera larvae on chickpea

negative effects on demographic parameters of $H$. armigera.

\section{Simulation of H. armigera larval dynamics}

A non-linear regression was employed to generate present models, illustrating $H$. armigera cumulative mean larval incidence in 16 locations over three seasons. Regression parameters in Boltzmann (a,b,c) and Logistic (a,b,c,d) non-linear equations were estimated and presented in Table 2. Through both the equations, cumulative incidence of $H$. armigera from various locations was well described. The -initial appearance (biofix) of $H$. armigera larvae on pigeonpea, across the locations and years was noticed in the range of 86-113 GDD (biofix - 40 SMW) accumulation, while in chickpea between 62 and 86 GDD (biofix - 43 SMW) accumulation. Both Eq.(1) and Eq.(2) were fitted with estimated regression parameters, observed and forecasted cumulative larval abundance in relation to accumulated GDD of $H$. armigera (Fig.2,3). Under natural (field) conditions, mean larval incidence on pigeonpea reached
ETL ( $\geq 1$ larvae per 3 branches) at 629 GDD while, Eq. (1) and Eq.(2) forecasted the ETL at 553 and 629 GDD, respectively (at LDT - $12.6{ }^{\circ} \mathrm{C}$ and biofix - $40 \mathrm{SMW}$ ). Similarly, natural cumulative mean larval incidence in chickpea reached ETL ( $\geq 1$ larvae per one meter row length) at 378 GDD accumulations whereas, Eq. (1) and Eq. (2) forecasted the ETLat 305 and 378 GDD accumulations, respectively (at LDT $-12.6{ }^{\circ} \mathrm{C}$ and BIOFIX - $43 \mathrm{SMW}$ ). The resulted residual (error term) from developed models were illustrated in scattered plots. Error terms $\left(\mu_{i}\right)$ were noticed in increasing trend throughout the $H$. armigera larval incidence in pigeonpea (Fig.4) and chickpea (Fig.5). In most cases, error term (resulted from residual) was normally distributed for the non-linear regression functions developed (Fig. 6 and 7).

The accumulated GDD estimated through logistic model for $H$. armigera in pigeonpea (629 GDD) and chickpea (378 GDD) crops to reach ETL was matched exactly with observed accumulated GDD needed for $H$. armigera under 


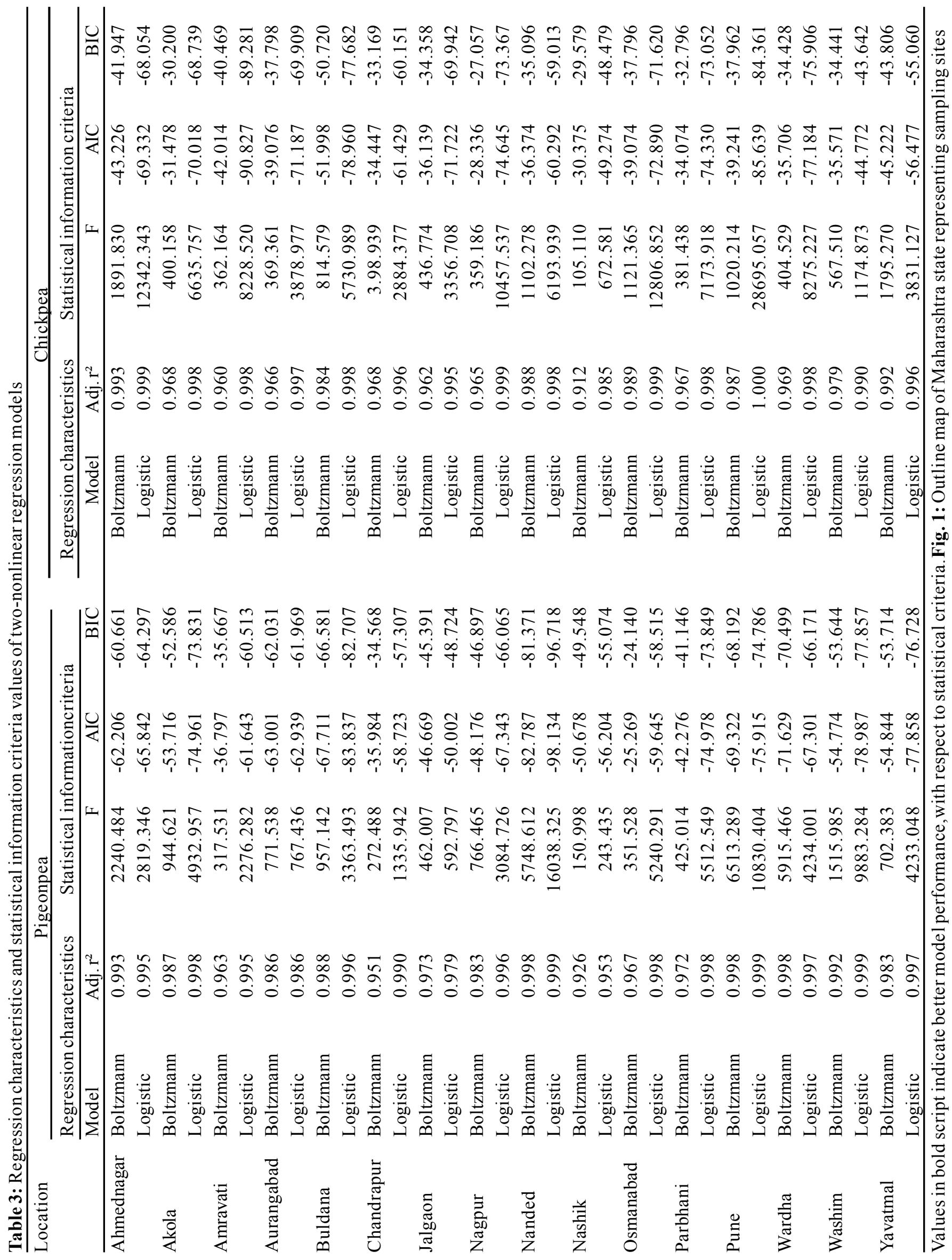




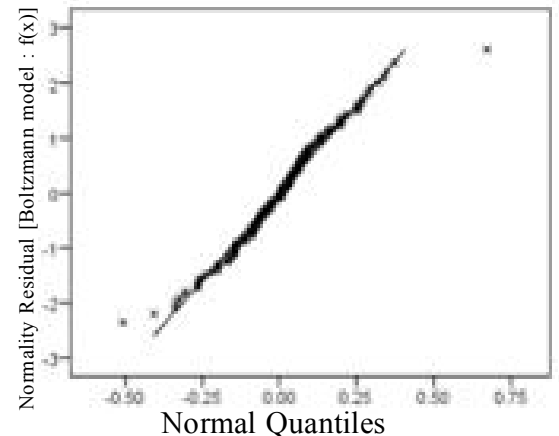

(a)

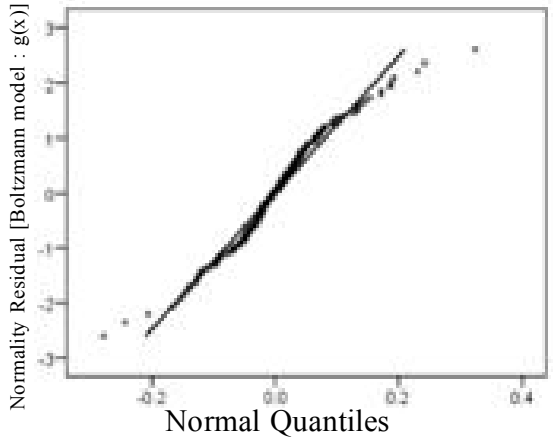

(b)

Fig. 6: Residual normality probability plot for generated (a) Boltzmann and (b) Logistic models in describing cumulative mean number of $H$. armigera larvae on pigeonpea

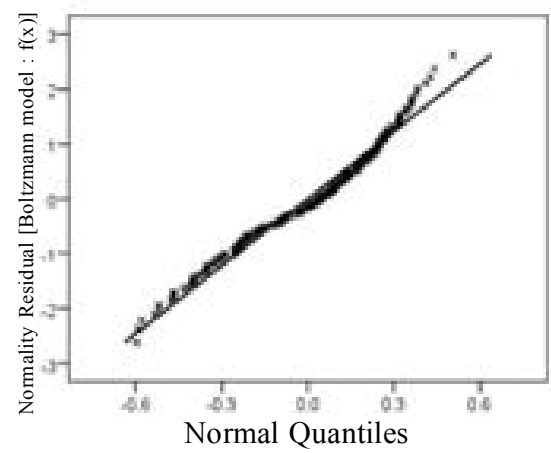

(a)

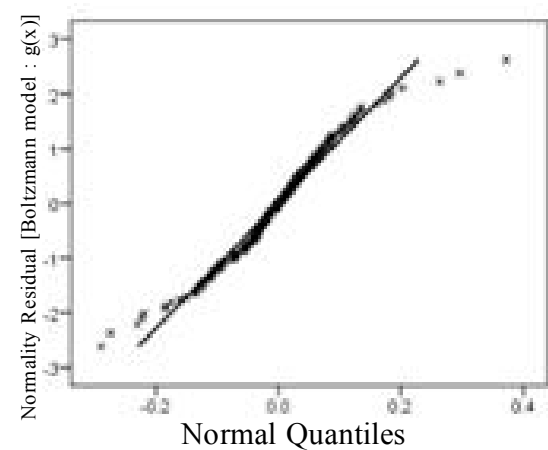

(b)

Fig. 7: Residual normality probability plot for generated (a) Boltzmann and (b) Logistic models in describing cumulative mean number of $H$. armigera larvae on chickpea

natural (field) conditions. However, Boltzmann model has estimated ETL too early than natural observation. This precise forecast behavior of logistic model was attributed to its parameter estimates. Additional inclusion of abiotic and biotic factors in logistic model, might improve the precision inforecasting $H$. armigera larval incidence. Shivani et al. (2019) experimental evidence demonstrated that $77 \%$ variability in $H$. armigera larval population on tomato was accounted by weather parameters particularly maximum temperature, morning and evening relative humidity. Furthermore, present models have been established on a single factor i.e., day air temperature and, incorporation of additional pest developmental events in relation to other weather parameters could improve robustness towards deep understanding of $H$. armigera ecology and survival as an agricultural pest.

\section{Statistical evaluation of models}

Both model performances were ranked based on Adj. $\mathrm{r}^{2}$ values. Higher accuracy in forecasting $H$. armigera larval incidence has been described by logistic model (Eq.(2)) in both crops across the locations, except Aurangabad and Wardha locations in pigeonpea where Boltzmann model (Eq.(1)) was found to fit better. Lower statistical information criteria (AIC and BIC) values for logistic models in presents study showed better performance over Boltzmann models in most of the locations across the crops and this observation was in consonance with Damos and Savopoulou-Soultani (2010). Estimated AIC and BIC values are based on OLS instead of likelihood, which additionally provide simplified statistical tools for model selection. Timely forecasting of $H$. armigera larval incidence based on larval phenology in pigeonpea and chickpea crops was quite useful for decision making in insect pest management.

Two key factors, accumulated GDD and 'biofix' aided in the development of effective forecast models. In the current study, logistic model outperformed the boltzmann model across the locations, seasons and crops. This implies that our logistic model can be a better alternative to the existing conventional models, which are developed based 
solely on temperature as a factor for forecasting $H$. armigeraon pigeonpea and chickpea in Maharashtra State, India.

\section{ACKNOWLEDGEMENTS}

Authors acknowledge the funding by State Department (Sanction orderNo. DDAPP/E\&T-7/CROPSAP 17-18/F.NOo.3/397/17) and access to datasets of 'Crop Pest Surveillance Project (CROPSAP) of Maharashtra'. The services of ICAR-CRIDA, state departmental staff, pest scouts, pest monitors and data entry operators rendered in implementation of the program are thankfully acknowledged.

\section{REFERENCES}

Akaike,H. (1974). Anewlook at the statisticalmodel identification. IEEE Trans. Auto. Con., 19: 716-723.

Akbar, S.M., Pavani, T., Nagaraja, T. and Sharma, H.C. (2016). Influence of $\mathrm{CO}_{2}$ and Temperature on Metabolism and Development of Helicoverpa armigera (Noctuidae: Lepidoptera). Environ. Entomol., 45(1): 229-36.

Burnham, K.P. and Anderson, D.R. (2002). In: Model Selection and Multimodel Inference: A Practical Information-Theoretic Approach, ( ${ }^{\text {nd }}$ Ed.). Springer-Verlag, New York, USA.

Chen, S., Blanford, J.I., Fleischer, S.J., Saunders, M.C. and Thomas M.B. (2013). Estimating West Nile virus transmission period in Pennsylvania using an optimized degree-day model. Vector Borne Zoo. Disea.,13:489497.

Chen, S., Fleischer, S.J., Saunders, M.C. and Thomas, M.B. (2015). The Influence of Diurnal Temperature Variation on Degree-Day Accumulation and Insect Life History. PLoSOne, 10(3): e0120772.

Damos, P.T. and Savopoulou-Soultani, M. (2010) Population dynamics of Anarsia lineatella in relation to crop damage and the development of economic injury levels. J. Appl. Entomol.,134 (2): 105-115.

Dhillon, M.K. and Sharma, H.C. (2007). Effect of storage temperature and duration on viability of eggs of Helicoverpa armigera (Lepidoptera: Noctuidae). Bull. Entomol. Res., 97: 55-59.

FAOSTAT. (2018). FAOStatistic Division. Retrieved from http:/ /faostat.fao.org/faostat/collections?version=ext\& hasbulk $0 \&$ subset $=$ agriculture. Last Accessed 03 June 2018.
Hartstack, A.W. Jr., Hollingsworth, J.P., Ridgeway, R.L. and Lopez, J.D. (1976). MOTHZV-2: Acomputer simulation of Heliothiszea and Heliothisvirescens population dynamics. In: User Manual, US Department of Agriculture, Agricultural Research Services, SR-127, Washington, D.C. pp. 55.

Huang, J. and Li, J. (2014). Effects of climate change on overwintering pupae of the cotton bollworm, Helicoverpa armigera (Hubner) (Lepidoptera: Noctuidae). Int. J. Biometeorol., 59(7): 863-876.

Johnson, M.L and Zalucki, M.P. (2007). Feeding and foraging behaviour of a generalist caterpillar: Are third instars just bigger versions of firsts? Bull. Entomol. Res., 97: 81-88.

Kuhrt, U., Samietz, J., Hohn, H. and Dorn, S. (2006). Modeling the phenology of codlingmoth: influence of habitat and thermoregulation. Agri. Ecosys. Environ.,117:29-36.

Kvalseth, T.O.(1985). Cautionary note about $\mathrm{R}^{2}$. The American Statistician, 3: 279-285.

Mironidis, G. K. and Savopoulou-Soultani, M. (2008). Development, Survivorship, and Reproduction of Helicoverpa armigera (Lepidoptera: Noctuidae) Under Constant andAlternating Temperatures. Environ. Entomol., 37(1):16-28.

Parmesan, C. (2007). Influences of species, latitudes and methodologies on estimates of phenological response to global warming. Global Change Biol., 13(9): 1860 1872.

Quinn, P.G. and Keough, M.J. (2002). Multiple and complex regression. In:Experimental Design and Data Analysis for Biologist. (Eds. P.G. Quinn and M.J. Keough) pp. 137-139, Cambridge University Press, Cambridge, UK.

Ram Manohar, P., Sharma, A.N. and Purushottam, S. (2019). Prediction of Helioverpa armigera (Hubner) larval population using weather based forewarning model in soybean. J. Agrometeorol., 21(4):494-498.

Rao, G.V.R., Rameshwar Rao, V. and Ghaffar, M.A. (2013). Handbook on Chickpea and Pigeonpea insect pests identification and management. Information Bulletin No. 57, International Crops Research Institute for the Semi-Arid Tropics, Patancheru, Andhra Pradesh, India. p. 96.

Richmond, J.A. and Bacheler, J.E. (1989). A comparison of two temperature-dependent developmental models for immature stages of the Nantucket pine tip moth 
(Lepidoptera: Tortricidae). J. Entomol. Sci., 24: 117123.

Schwartz, S.A.(1978). Acomprehensive system for item analysis in psychological scale construction. J. Edu. Measu., 15(2): 117.

Sharpe, P.J. and De Michele, D. W. (1977). Reaction kinetics of poikilotherm development. J. Theor. Biol., 64: 649670.

Shivani, K., Krishna, R., Gaurav, S. and Anil Kumar (2019). Influence of prevailing weather parameters on population dynamics of fruit borer, Helicoverpa armigera (Hübner) on tomato in Haryana. $J$. Agrometeorol., 21(2):193-196.

Sokal, R.R. and Rohlf,F.J. (1995). Biometry: The principles and practice of statistics in biological research. ( $3^{\text {rd }}$ Ed.) Freeman, W.H. 1969, San Francisco, USA.p.776

SPSS. (1997). SPSS Inc., Version 1.14. SPSS, Chicago, IL.

Srinivasa Rao, M. and Prasad, T.V. (2020). Temperature based phenology model for predicting establishment and survival of Spodoptera litura (Fab.) on groundnut during climate change scenario in India.J. Agrometeorol., 22(1):24-32.
Srinivasa Rao, M., Manimanjari, D., Vennila, S., Shaila, O., Abdul Khadar, B., Venkateswar Rao, K., Srinivas, K., Murali Krishna Raju, B., Rama Rao, C.A. and Srinivasa Rao, C. (2016). Prediction of Helicoverpa armigera Hubner on pigeonpea during future climate change periods using MarkSim multi model data. Agric. Forest Meteorol., 228: $130-138$.

Wagner, T.L., Wu, H.I., Sharpe, P.J.H., Schoolfield, R.M. and Coulson, R.N. (1984). Modeling insect development rates: Aliterature review and application of a biophysical model. Ann. Entomol. Soc. Amer., 77: 208-225.

Westgarth-Smith, A.R., Leroy, S.A.G., Collins, P.E.F. and Harrington, R. (2007). Temporal variations in English populations of a forest insect pest, the green spruce aphid (Elatobium abietinum), associated with the North Atlantic oscillation and global warming. Quat. Int., 173: 153-160.

Yenagi, B.S., Patil, V.C., Biradar, D.P. and Khadi, B.M. (2011). Refuge cropping systems for Helicoverpa armigera (Hubner) resistance management in $\mathrm{Bt}$ cotton (Gossypium hirsutum). Aca. J. Entomol., 4(3): 102-107.

Ziter, C., Robinson, E.A. and Jonathan, N.A. (2012). Climate change and voltinism in California insect pest species: Sensitivity to location, scenario and climate model choice. Global Change Biol.,18: 2771-2780. 